\title{
Cost-effectiveness of inhala- tional, balanced and total intravenous anaesthesia for ambulatory knee surgery
}

\author{
Jamal A Alhashemi MB BS, \\ Donald R Miller MD FRCPC, \\ Heather V O'Brien MD FRCPC, \\ Kathryn A Hull RN
}

Purpose: A randomized, blinded clinical trial was undertaken to compare recovery characteristics and cost-benefits associated with three general anaesthetic techniques for arthroscopic knee surgery in an ambulatory care setting.

Methods: Ninety three, ASA Physical Status I-II patients were randomly allocated to receive one of three types of general anaesthesia: IsofluranefentanyI/ $\mathrm{N}_{2} \mathrm{O}$ (Group $\mathrm{INH}$ ); alfentanil/N.O (Group BAL); or propofol/alfentanil/O, (Group TIVA). Postoperative recovery profiles were evaluated at 30,60, 90 and 120 min after emergence from anaesthesia, and direct and indirect costs of each anaesthetic were compared.

Results: The most rapid emergence was observed in Group BAL $(2.2 \pm 1.5 \mathrm{~min}, P<0.0001$ compared with groups INH and TIVA), although the incidence of post-operative nausea and vomiting was also highest in this group ( $P=0.02$ compared with groups INH and TIVA). However, overall patient satisfaction, and mean times to discharge from the Post Anaesthesia Recovery Unit and hospital, were rapid and similar in all three groups. During anaesthesia which lasted $40-45 \mathrm{~min}$, nearly a four-fold difference was observed in the direct costs of anaesthetic drugs: $\$ 16.4 \pm 4.4$ (Group INH). $\$ 45.3 \pm 11.4$ (Group BAL) and $\$ 63.4 \pm 17.9$ (Group TIVA, $P<0.001$ between groups); while indirect costs were similar.

Conclusions: For arthroscopic knee surgery. INH anaesthesia with isoflurane/fentany $/ N_{2} \mathrm{O}$ is associated with sımilar hospital discharge times, and comparable levels of patient satisfaction as either BAL or TIVA. While indirect costs were similar, lower direct costs suggest that there may be a pharmacoeconomic benefit associated with the use of a "standard" isofluraneffentany/ $\mathrm{N}, \mathrm{O}$ anaesthetic in certain day care surgery procedures.

Objectif : Cette étude clınique aléatoire et à l'aveugle visait à comparer les caractéristiques de la récupération et les valeurs coûts/bénéfices associées à trois techniques d'anesthésie générale réalisées pour la chirurgie arthroscopique du genou dans un encadrement de chinurgie ambulatoire.

Méthodes : Quatre-vingt-treize patients ASA I et Il étaient répartis aléatoirement pour recevoir une des trois techniques d'anesthésie générale suivantes : isofluraneffentanyl/ $\mathrm{N}_{2} \mathrm{O}$ (groupe $\mathrm{INH}$ ); alfentanil/N2O (groupe $B A L$ ) : ou propofol/alfentanil (groupe TIVA). Le profil de la récupération postopératoire était évalué à 30, 60, 90 et 120 min après le réveil et les coûts directs et indirects de chaque technique étaient comparés.

Résultats : Un réveil plus rapide était observé dans le groupe BAL $(2,2 \pm 1,5 \mathrm{~min}, P<0,0001)$ comparativement au groupe INH et TIVA, mais, dans ce groupe, l'incidence des nausées et des vomissements postopératoires était aussi la plus élevée $(P=0.02)$ comparativement aux groupes INH et TIVA. Cependant, la satisfaction générale du patient était élevée et la durée moyenne du séjour à l'unité des soins postanesthésiques et à l'hôpital étaient identiques pour les trois groupes. Pendant l'anesthésie. qui durait de 40 à $45 \mathrm{~min}$, on a constaté que les coûts directs des agents quadruplaient selon la technique : $16.4 \pm 4.4$ (groupe $\mathrm{NNH}$ ), 45.3 $\pm 11,4$ (groupe BAL) et 63.4 \pm 7.8 (groupe TIVA, $P<0,001$ entre les groupes), alors que les coûts indirects demeuraient les mêmes.

Conclusion : Pour la chirurgie arthroscopique du genou, l'anesthésie INH à l'isoflurane/fentanyl/N2O est associée à la même durée de séjour à l'hôpital et, pour le patient, à un degré de satisfaction comparable aux techniques BAL et TIVA. Alors que les coûts indirects sont les mêmes, des coûts directs inférieurs suggèrent que, sous l'aspect pharmacologique, l'utilisation d'une l'anesthésie standard isoflurane/fentanyl pourrait être avantageuse pour certaines interventions chirurgicales ambulatoires.

From the Department of Anaesthesia, Ottawa General Hospital and the University of Ottawa, Ottawa General Hospital, 501 Smyth Road, Ottawa, Ontario KIH 8L6. Presented in part at The Canadian Anaesthetists' Society Meeting, Ottawa, Ontario; June 1995. Supported by a rescarch grant from Janssen-Ortho Inc., Canada.

Address correspondence to: Dr. Donald R. Miller. TEL: 613-737-8187; FAX: 613-737-8189; E-mail: dmilleraogh.ca.

Accepted for publication October 3, 1996. 


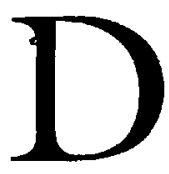
URING the past several years, health care "reform" has resulted in funding cutbacks in many aspects of hospital-based care. As hospitals struggle to cope with eroding budgets, the number of available cost-saving options have been steadily declining. In this milieu, pharmacy budgets, which generally comprise between four to eight percent of total budgets in most hospitals, have emerged as a readily identifiable target for

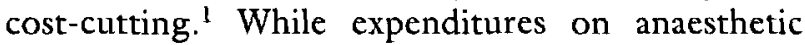
drugs represent a relatively small proportion of this component (approximately 5-10\%), ${ }^{2}$ cost-minimization efforts, including substitutions and restrictions on certain drugs, and the introduction of educational programmes, have been introduced in many departments of anaesthesia. ${ }^{2,3}$ Although such programmes are appealing from an administrative perspective, one obvious challenge has been the difficulty in evaluating their overall cost-effectiveness.

Recently, the concept of value-based anaesthesia care was introduced, referring to delivery of the best possible care at a reasonable cost. ${ }^{4}$ Despite the importance of this concept, at the present time there is a relative paucity of data regarding the cost-effectiveness or cost-benefit of the drugs and techniques most commonly used in the day-to-day practice of anaesthesia. Whereas some studies suggest that the use of shortacting drugs such as propofol may provide an overall economic benefit for a number of out-patient procedures, ${ }^{5}$ such drugs may not achieve a cost-benefit during longer surgery. ${ }^{6}$ In addition, a demonstrable cost-benefit for the use of the short-acting opioid alfentanil, has never been established.

To address these concerns, a double-blind trial was designed, using a series of recovery scoring systems and a cost-benefit analysis. The purpose was to evaluate the recovery characteristics and cost-benefit of total intravenous anaesthesia with propofol/alfentanil/ $\mathrm{O}_{2}$, and a balanced technique using nitrous oxide/alfentanil, compared with a "standard" inhalational anaesthetic consisting of nitrous oxide/isoflurane/fentanyl, in patients undergoing arthroscopic knee surgery in an ambulatory care setting.

\section{Methods}

\section{Study Population}

This was a prospective, randomized, double-blind clinical trial. Blinding was achieved by precluding the trained observer, who recorded all post-operative data, from gaining any knowledge of the intra-operative anaesthetic care. Sample sizé was calculated based upon absolute differences of combined direct and indirect costs of the three anaesthetic techniques, assuming
$90 \%$ statistical power and an alpha value of 0.05 . In total, 93 eligible patients participated, after giving written informed consent to the protocol approved by the Research Ethics Board of the Ottawa General Hospital. Subjects were ASA Physical Status I or II, scheduled to undergo arthroscopic knee surgery, and electing general anaesthesia. Exclusion resulted for any one or more of the following reasons: patient preference for regional anaesthesia; age $<20$ or $>60 \mathrm{yr}$; body mass index either $<20$ or $>30 \mathrm{~kg} \cdot \mathrm{m}^{-2}$; current or chronic use of benzodiazepines or other sedative-hypnotics; excessive alcohol intake; moderate or severe cardiac or respiratory disease; severe or uncontrolled hypertension; known allergy to any of the study medications; or chronic use of drugs known to interfere with the metabolism or clinical effects of the study medications.

\section{Anaesthetic Technique}

Consistent with established surgical day care procedures at the study institution, no premedication was given. In the operating room, routine monitors were applied, and an $18 \mathrm{~g}$ peripheral iv cannula was secured. Patients were then allocated, according to a computergenerated randomization schedule, into one of the following three study groups:

\section{Group INH: Inhalational Anaesthesia \\ Group BAL: Balanced Anaesthesia \\ Group TIVA: Total Intravenous Anaesthesia}

All patients received $0.03 \mathrm{mg} \cdot \mathrm{kg}^{-1}$ midazolam $i v$, and $0.05 \mathrm{mg} \cdot \mathrm{kg}^{-1} \mathrm{~d}$-tubocurarine for defasciculation. Three minutes later, anaesthesia was induced using thiopentone and fentanyl in group INH, and with propofol and alfentanil in groups BAL and TIVA, according to the doses listed in Table I. Every subject received $1.5 \mathrm{mg} \cdot \mathrm{kg}^{-1}$ iv succinylcholine to facilitate tracheal intubation, followed by $0.2-0.4 \mathrm{mg} \cdot \mathrm{kg}^{-1}$ ip atracurium for muscle relaxation during the remainder of the procedure.

Maintenance of anaesthesia was provided with $\mathrm{N}_{2} \mathrm{O}$ $70 \%$ and isoflurane $0.5-1.0 \%$ end-tidal (ET) in group

TABLE I Anaesthetic Techniques

\begin{tabular}{|c|c|c|c|}
\hline \multicolumn{2}{|c|}{ GROUP } & Induction & Maintenance \\
\hline INH & Mid/Thio/Fen & \multicolumn{2}{|c|}{$\mathrm{N}_{2} \mathrm{O}$; isoflurane $0.5-1.0 \%(\mathrm{ET})$} \\
\hline BAL & $\mathrm{Mid} /$ Pro $/ \mathrm{Alf}_{\mathrm{j}}$ & \multicolumn{2}{|c|}{$\mathrm{N}_{2} \mathrm{O} ; \mathrm{Alf}_{\mathrm{s}}$ prn } \\
\hline TIVA & $\mathrm{Mid} /$ Pro/Alf $_{j}$ & \multicolumn{2}{|c|}{ Pro infusion $140 \mu \mathrm{g} \cdot \mathrm{kg}^{-1} \cdot \min ^{-1} ; \mathrm{Alf}_{\mathrm{S}} \mathrm{prn}$} \\
\hline
\end{tabular}

$\mathrm{INH}=$ inhalational anaesthesia; $\mathrm{BAL}=$ balanced anaesthesia; TIVA $=$ total intravenous anaesthesia; Mid=midazolam 0.03 $\mathrm{mg} \cdot \mathrm{kg}^{-1}$; Thio=thiopentone 3-5 $\mathrm{mg} \cdot \mathrm{kg}^{-1}$; Pro=propofol $\mathrm{l}-\mathrm{l} .5$ $\mathrm{mg} \cdot \mathrm{kg}^{-1}$;

Fen=fentanyl $1.5 \mu \mathrm{g} \cdot \mathrm{kg}^{-1} ;$ Alf $=$ alfentanil $20 \mu \mathrm{g} \cdot \mathrm{kg}^{-1}$; $\mathrm{Alf}_{\mathrm{S}}=$ alfentanil $7-15 \mu \mathrm{g} \cdot \mathrm{kg}^{-1}$. 
INH. Patients in the BAL group received $\mathrm{N}_{2} \mathrm{O}, 70 \%$ supplemented with intermittent boluses of 7-15

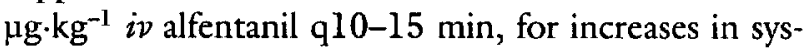
tolic blood pressure (SBP) and/or heart rate (HR) exceeding $20 \%$ of individual preoperative baseline values, determined from the mean of two recordings in the Day Care Unit. Patients in group TIVA also received $7-15 \mu \mathrm{g} \cdot \mathrm{kg}^{-1}$ iv alfentanil boluses as outlined for group $\mathrm{BAL}$, in conjunction with a continuous infusion of propofol, but without $\mathrm{N}_{2} \mathrm{O}$. Following induction of anaesthesia in group TIVA, propofol was administered at a rate of $160 \mu \mathrm{g} \cdot \mathrm{kg}^{-1} \cdot \mathrm{min}^{-1}$ for the first $10 \mathrm{~min}$, followed by a continuous infusion maintained at $140 \mu \mathrm{g} \cdot \mathrm{kg}^{-1} \cdot \mathrm{min}^{-1}$ for the duration of the procedure. Thus, anaesthetic depth was modified by adjusting the isoflurane concentration in group INH, and by titrating alfentanil in groups BAL and TIVA, to maintain SBP and HR within $\pm 20 \%$ of pre-induction baseline values.

In anticipation of the end of surgery, isoflurane and propofol were discontinued within five min of skin closure in groups INH and TIVA, respectively, while $\mathrm{N}_{2} \mathrm{O}$ was maintained until the end of surgery in Group BAL. Neuromuscular block was reversed in all groups using a combination of $0.5 \mathrm{mg} \cdot \mathrm{kg}^{-1}$ edrophonium iv and $20 \mu \mathrm{g} \cdot \mathrm{kg}^{-1}$ atropine $i v$, while the lungs were ventilated with $100 \% \mathrm{O}_{2}$. Tracheal extubation took place when patients were able to open their eyes either spontaneously or to command. Any patient who did not resume spontaneous respiration within $10 \mathrm{~min}$ of the completion of anaesthesia, received $40 \mathrm{\mu g}$ naloxone iv. Subjects were then transferred to the Post-Anaesthesia Care Unit (PACU), where postoperatively, morphine was given in $2 \mathrm{mg}$ increments iv prn for pain, and $25 \mathrm{mg}$ dimenhydrinate $i v$ prn was given to treat nausea and/or vomiting.

\section{Measurements}

Intraoperatively, end-tidal isoflurane concentration was recorded every five minutes in group INH, and for all three groups the cumulative amounts of all administered $i v$ anaesthetic drugs and muscle relaxants were calculated. In addition, SBP and HR were recorded at baseline, one min after completion of the induction sequence, then at one, two, and five min following tracheal intubation, and every five minutes thereafter throughout surgery.

Assessment of recovery began in the operating room by recording the time to spontaneous eye opening, and the time of response to verbal commands. Postoperatively, a blinded observer evaluated the patient's recovery profile upon arrival in PACU, and every 15 min thereafter until the patient was considered fit for hospital discharge. Recovery was assessed using a modified Aldrete scoring system ${ }^{7}$ and the post-anaesthesia discharge scoring system (PADS). ${ }^{8}$ In addition, the Observer's Assessment of Alertness/Sedation scale, ${ }^{9}$ and Trieger dot test ${ }^{10}$ were performed preoperatively (baseline), and every $30 \mathrm{~min}$ following the patient's arrival in PACU, for a period of three hours.

The incidences of nausea and vomiting in-hospital, and within $24 \mathrm{hr}$ after hospital discharge, were compared. Other potential adverse events, such as respiratory depression and awareness with recall, were recorded. A subjective evaluation of the quality of recovery was performed by conducting a telephone interview, based on a questionnaire, 24-36 hr postoperatively. During this interview, patients were asked to rate their anaesthetic experience on a three-point scale, as being either pleasant, tolerable, or unpleasant. In addition, patients were asked to describe when they were able to resume their normal activities of daily living, defined as the ability to read and remember newspaper articles, and/or engage in house activity, or being able to care for a small child.

A cost-benefit comparison of the three anaesthetic techniques was provided by directly comparing anaesthetic drug costs (both administered and wasted), based on the unit price of each medication (as of August 1995). Isoflurane expenditures calculated were using the formula:

$\mathrm{ml}$ consumed $=$ fresh gas flow rate $\left(\mathrm{L} \cdot \mathrm{min}^{-1}\right) \times[\%$ isoflurane $] / 20$

and multiplying this figure by the drug's unit price cost. ${ }^{11}$ Expenditures on nitrous oxide and oxygen were excluded. Indirect costs, including expenditures on analgesic and antiemetic medications administered in the PACU were incorporated in the analysis. Possible indirect benefits were evaluated by assessing nursing workload requirements of each patient in the PACU and Day Care Unit (DCU), based on the number of bedside visits for each patient, and the cumulative nursing time. Nursing costs were then calculated according to the average salary of middle rank nurses in both units during the period of the study. Finally, the potential fiscal consequences of delayed recovery were considered by documenting the incidence of delayed hospital discharge (in-hospital time >three hours following emergence from anaesthesia) or unplanned admission to hospital.

\section{Statistical Analysis}

Demographic data were compared using the Chisquare statistic. Haemodynamic variables were assessed using repeated measures analysis of variance ( $\mathrm{Rm}$ ANOVA). Recovery variables, anaesthetic drug costs, and nursing workload were evaluated using analysis of variance (ANOVA), and the Chi-square sta- 
tistic, where appropriate. Adverse events and individual patient ratings of anaesthetic experiences were analyzed using either the Chi-square statistic or Fisher's exact test. Finally, the Kruskal-Wallis test and the Student-Newman-Keuls test were performed to analyze the results of the Observer's Assessment of Alertness/Sedation score, and Trieger Dot test.

The Chi-square test was done using the Primer of Biostatistics, ${ }^{\oplus}$ version 3.01 for IBM PC (McGrawHill, Inc.). The remainder of statistical analyses were performed using SigmaStat ${ }^{\circledR}$ for windows statistical package, version 1.0 (Jandel Scientific, San Rafael, CA). Data throughout the text and tables are presented as mean $\pm S D$, and statistical significance was assumed when $P<0.05$.

\section{Results}

\section{Patient Population and Intraoperative Course}

Demographic characteristics were similar among groups, with a mean patient age of $38.3 \pm 11.3 \mathrm{yr}$ (Table II). Although there were more men than women in groups BAL and TIVA, the sex distribution was not different. The majority of subjects were ASA I, and all 93 subjects completed the study protocol. The mean duration of anaesthesia was $43.5 \pm 1.4 \mathrm{~min}$ (Table III), and no

TABLE II Demographic Data

\begin{tabular}{llll}
\hline GROUP & $\begin{array}{l}\text { INH } \\
(n=31)\end{array}$ & $\begin{array}{l}B A L \\
(n=31)\end{array}$ & $\begin{array}{l}\text { TIVA } \\
(n=31)\end{array}$ \\
\hline Age (yr) & $37.4 \pm 11.0$ & $38.6 \pm 11.1$ & $38.8 \pm 11.8$ \\
Sex (M/F) & $16 / 15$ & $20 / 11$ & $22 / 9$ \\
Weight (kg) & $74.3 \pm 14.1$ & $76.1 \pm 11.1$ & $81.2 \pm 14.6$ \\
ASA status (I/II) & $21 / 10$ & $25 / 6$ & $24 / 7$ \\
\hline
\end{tabular}

$\mathrm{INH}=$ inhalational anaesthesia; $\mathrm{BAL}=$ balanced anaesthesia; TrVA = total intravenous anacsthesia.

TABLE III Recovery Characteristics

\begin{tabular}{llll}
\hline GROUP & $\begin{array}{l}I N H \\
(n=31)\end{array}$ & $\begin{array}{l}B A L \\
(n=31)\end{array}$ & $\begin{array}{l}\text { TNA } \\
(n=31)\end{array}$ \\
\hline Anaesthesia Duration (min) & $41.6 \pm 14.3$ & $42.9 \pm 12.5$ & $46.1 \pm 14.6$ \\
Recovery Profile: & & & \\
Eye Opening (min) & $8.5 \pm 4.8$ & $2.2 \pm 1.5^{*}$ & $8.8 \pm 4.4$ \\
& $(2-22)$ & $(0-7)$ & $(2-8)$ \\
Respond to command (min) $8.9 \pm 5.4$ & $3.0 \pm 3.2^{*}$ & $9.2 \pm 4.5$ \\
Time to extubation (min) & $8.1 \pm 5.2$ & $3.3 \pm 3.0^{*}$ & $8.3 \pm 5.1$ \\
Discharge from OR (min) & $9.7 \pm 4.9$ & $6.0 \pm 3.2^{*}$ & $9.8 \pm 4.8$ \\
& $(3-24)$ & $(2-18)$ & $(3-19)$ \\
PACU rime (min) & $57.2 \pm 22.2$ & $56.1 \pm 23.3$ & $59.0 \pm 15.5$ \\
Nursing visits (n) & $10 \pm 2$ & $10 \pm 2$ & $10 \pm 2$ \\
PADS 29 (min) & $100.8 \pm 33.496 .5 \pm 29.1$ & $92.1 \pm 18.7$ \\
Discharge time (min) & $135.7 \pm 34.8$ & $130.6 \pm 29.5$ & $124.7 \pm 17.2$ \\
& $(91-222)$ & $(82-212)$ & $(92-165)$ \\
\hline
\end{tabular}

$\mathrm{INH}=$ inhalational anaesthesia; $\mathrm{BAL}=$ balanced anaesthesia; TIVA $=$ total intravenous anaesthesia;

${ }^{*} P<0.0001$, different from INH and TIVA.

PADS= post-anaesthesia discharge score. ${ }^{9}$ patient experienced surgical or anaesthesia-related complications of clinical importance. While mean $H R$ values were greater throughout surgery in Group INH patients compared with groups BAL and TIVA $(P<0.05), \mathrm{HR}$ remained below $90 \mathrm{bpm}$ in all three groups throughout surgery. Only in response to tracheal intubation did SBP increase in group INH $(P<0.05)$; otherwise SBP values were similar in all three groups from $\mathrm{NT}+5$ to INT + 45 (Figure).

\section{Recovery Characteristics}

In Group BAL, mean times to eye opening $(2.2 \pm 1.5$ $\mathrm{min})$ and response to command $(3.0 \pm 3.2 \mathrm{~min})$ were shorter than the corresponding times in both other groups $(P<0.001$, Table III). In addition, the tracheas of patients in group BAL were extubated and the patients were discharged from the operating room more quickly than those in the INH and TIVA groups $(P<0.0001)$. Despite differences in early recovery times, the length of PACU stay, the number of nursing visits, times required to achieve a PADS score $\geq 9$, and actual hospital discharge times, were similar in all three groups (Table III). Of further importance, no patient had to stay in hospital beyond three hours, and there were no unplanned admissions to hospital.

Comparison of psychomotor aspects of recovery at $t=30 \mathrm{~min}$ revealed lower Trieger Dot scores in Group BAL, than in groups INH and TIVA $(P<0.05$, Table IV). While this difference reflected a more rapid

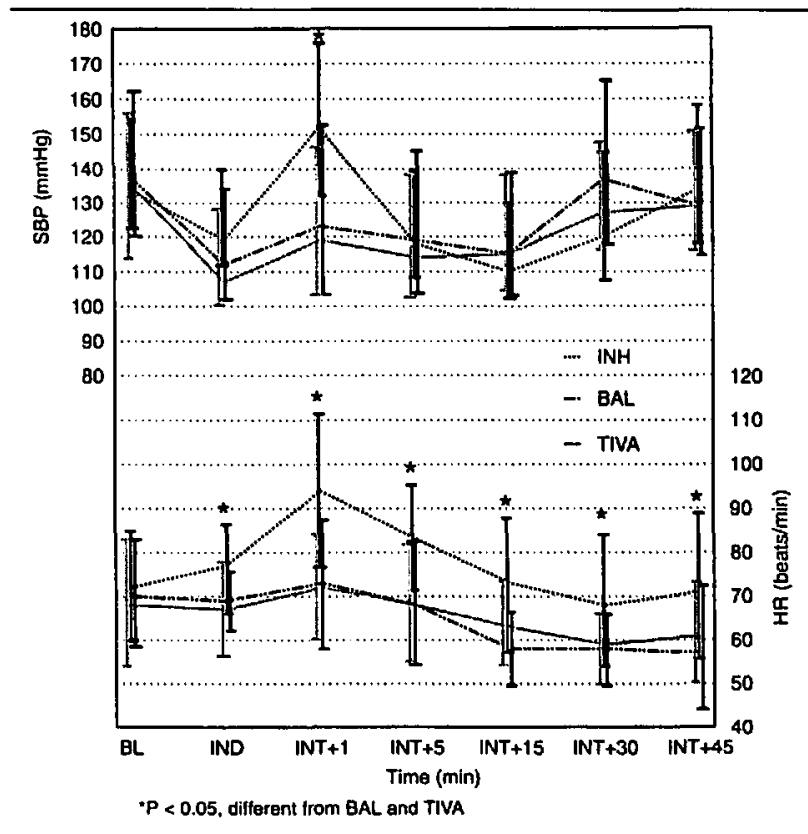

FIGURE Systolic blood pressure (SBP) and heart rate (HR) at baseline, one min after induction (IND), and $1,5,15,30$ and 45 min after tracheal intubation (INT $+1 \ldots$ INT +45 ). 
TABLE IV Psychomotor Evaluation

\begin{tabular}{llll}
\hline GROUP & $\begin{array}{l}I N H \\
(n=31)\end{array}$ & $\begin{array}{l}B A L \\
(n=31)\end{array}$ & $\begin{array}{l}\text { TIVA } \\
(n=31)\end{array}$ \\
\hline Trieger Dot Test (dots missed): & & & \\
preop baseline (n) & $2.6 \pm 2.5$ & $2.4 \pm 2.9$ & $3.1 \pm 3.0$ \\
30 min postop (n) & $15.1 \pm 8.3$ & $9.6 \pm 7.1^{\star}$ & $14.6 \pm 8.9$ \\
60 min postop (n) & $6.9 \pm 5.4$ & $7.6 \pm 5.4$ & $6.5 \pm 5.7$ \\
90 min postop (n) & $4.2 \pm 5.2$ & $5.2 \pm 4.5$ & $5.0 \pm 5.1$ \\
OAA/S Score: & & & \\
preop baseline (median /75\%) & $5 / 5$ & $5 / 5$ & $5 / 5$ \\
30 minutes postop (median /75\%) & $4 / 4$ & $4 / 5$ & $4 / 4$ \\
60 minutes postop (median /75\%) & $4 / 5$ & $5 / 5$ & $4 / 5$ \\
\hline
\end{tabular}

INH=inhalational anaesthesia; $B A L=b a l a n c e d$ anaesthesia; TIVA-total intravenous anaesthesia; preop = preoperative; postop $=$ postoperative

${ }^{*} P<0.05$, different from both INH and TIVA.

return of psychomotor function in Group BAL, Trieger Dot scores were similar among the three groups by the end of the first postoperative hour (Table IV). Interestingly, median $\mathrm{OAA} / \mathrm{S}$ scores were ' 4 ' in all groups after 30 min of recovery, and only in group BAL had median scores recovered to the baseline level of ' 5 ' by the end of the first postoperative hour.

\section{Quality of Recovery}

Forty-eight percent of patients in group BAL experienced nausea and/or vomiting while in hospital (Table V), but only half of these individuals required treatment with anti-emetic medications $(P<0.02$ vs TIVA). Respiratory depression (apnea $>10 \mathrm{~min}$ following discontinuation of anaesthesia) was observed in two patients in group INH, and seven patients in group TIVA $(P<0.02$ different from INH) while in the operating room. These patients received a single dose of naloxone $i v$, and none had recurrence of apnea following the initial treatment. Other potential adverse events were not observed in any patient, with the exception of one case of mild pruritus in group BAL, which resolved spontaneously (Table V).

Time to resumption of normal activities of daily living was achieved in less than 24 hrs in all groups (Table VI), and $98 \%$ of all patients rated their anaesthetic experience as having been either pleasant or tolerable. Of those who had received a previous general anaesthetic, more than half regarded their current experience as having been superior, or at least the same as, their previous anaesthetic experience (Table VI).

\section{Costs of Anaesthesia and Postoperative Care}

Total intravenous anaesthesia and BAL anaesthesia were the most expensive anaesthetics, with mean costs per case of $\$ 63.4 \pm 1.91$ and $\$ 45.3 \pm 11.42$, respec-
TABLE V Postoperative Adverse Events

\begin{tabular}{llll}
\hline GROUP & $\begin{array}{l}\text { INH } \\
(n=31)\end{array}$ & $\begin{array}{l}\text { BAL } \\
(n=31)\end{array}$ & $\begin{array}{l}\text { TIVA } \\
(n=31)\end{array}$ \\
\hline Nausea/Vomiting (\%) & 23 & $48^{*}$ & 16 \\
Respiratory Depression (n) & 2 & 0 & $7^{\dagger}$ \\
Pruritus (n) & 0 & 1 & 0 \\
Awareness with Recall (n) & 0 & 0 & 0 \\
Others (n) & 0 & 0 & 0 \\
\hline
\end{tabular}

$\mathrm{NNH}=$ inhalational anaesthesia; $\mathrm{BAL}=$ balanced anaesthesia;

TIVA = total intravenous anaesthesia; ${ }^{*} P<0.02$, different from TIVA $t_{P}<0.02$, different from BAL.

TABLE VI Qualitative Assessment of Recovery and Anaesthetic Experience

\begin{tabular}{llll}
\hline GROUP & $\begin{array}{l}I N H \\
(n=31)\end{array}$ & $\begin{array}{l}B A L \\
(n=31)\end{array}$ & $\begin{array}{l}\text { TIVA } \\
(n=31)\end{array}$ \\
\hline $\begin{array}{l}\text { Resumption of normal } \\
\text { activity (hr) }\end{array}$ & $20.1 \pm 15.7$ & $17.4 \pm 14.3$ & $16.7 \pm 22.3$ \\
$\begin{array}{c}\text { Anaesthetic experience } \\
\quad(\mathrm{P} / \mathrm{T} / \mathrm{U})\end{array}$ & $26 / 4 / 1$ & $21 / 9 / 1$ & $26 / 5 / 0$ \\
$\begin{array}{l}\text { Rating to past experiences } \\
(\mathrm{B} / \mathrm{S} / \mathrm{W} / \mathrm{N})\end{array}$ & $21 / 3 / 0 / 7$ & $9 / 4 / 5 / 13$ & $15 / 5 / 2 / 9$ \\
\hline
\end{tabular}

$\mathrm{INH}=$ inhalational anaesthesia; $\mathrm{BAL}=$ balanced anaesthesia; TIVA = total intravenous anaesthesia;

$\mathrm{P}=$ pleasant; $\mathrm{T}=$ tolerable; $\mathrm{U}=$ unpleasant $\mathrm{B}=$ betrer $\mathrm{S}=\mathrm{Same} ;$ $\mathrm{W}=$ Worse $; \mathrm{N}=$ no previous anaesthetic experience.

TABLE VII Costs of Anaesthesia and Postoperative Care

\begin{tabular}{|c|c|c|c|}
\hline GROUP & $\begin{array}{l}I N H \\
(n=31)\end{array}$ & $\begin{array}{l}B A L \\
(n=3 I)\end{array}$ & $\begin{array}{l}\text { TIVA } \\
(n=31)\end{array}$ \\
\hline \multicolumn{4}{|l|}{ Anaesthetic drugs : } \\
\hline Utilization per case $(\$)$ & $16.4 \pm 4.4^{\star}$ & $45.3 \pm 11.4^{*}$ & $63.4 \pm 17.9^{\star}$ \\
\hline Utilization per hour $(\$)$ & $26.9 \pm 10.0^{*}$ & $66.0 \pm 15.3^{*}$ & $86.4 \pm 24.6^{*}$ \\
\hline Wastage per case $(\$)$ & $1.4 \pm 1.5^{* *}$ & $3.7 \pm 4.6$ & $6.3 \pm 4.6^{\dagger}$ \\
\hline \multicolumn{4}{|l|}{ Nursing costs : } \\
\hline PACU $(\$)$ & $8.6 \pm 2.7$ & $8.5 \pm 3.4$ & $8.5 \pm 3.4$ \\
\hline $\operatorname{DCU}(\$)$ & $10.1 \pm 3.3$ & $9.5 \pm 2.2$ & $9.0 \pm 2.4$ \\
\hline Total $(\$)$ & $18.7 \pm 3.9$ & $17.9 \pm 4.4$ & $17.5 \pm 5.2$ \\
\hline \multicolumn{4}{|l|}{ Postoperative drugs : } \\
\hline Morphine (\$) & $0.1 \pm 0.1$ & $0.1 \pm 0.1$ & $0.1 \pm 0.1$ \\
\hline Dimenhydrinate (\$) & $0.4 \pm 0.1$ & $0.5 \pm 0.3$ & $0.2 \pm 0.0$ \\
\hline Total cost per case $(\$)$ & $36.4 \pm 5.3$ & $66.5 \pm 11.7^{\star}$ & $86.2 \pm 20.6^{*}$ \\
\hline
\end{tabular}

$\mathrm{INH}=$ inhalational anaesthesia; $\mathrm{BAL}=$ balanced anaesthesia; TIVA $=$ total intravenous anaesthesia;

$\mathrm{PACU}=$ post-anaesthesia care unit; $\mathrm{DCU}=$ day care unit.

* $P<0.001$, different from each other;

${ }^{\star *} P<0.02$, different from $\mathrm{BAL}$;

t $P<0.001$, different from INH.

tively. Inhalational anaesthesia was the least expensive, with a mean cost of $\$ 16.4 \pm 4.43(P<0.001$ different from BAL and TIVA). Differences between techniques persisted after cost adjustment for time (Table VII). Indirect costs, comprising nursing salaries 
and expenditures on medications given in PACU and DCU for the treatment of pain, and/or nausea and vomiting, were similar amongst groups (Table VII).

\section{Discussion}

During the past several years, an exponential growth in Day Care Surgery has been facilitated, in part, by the introduction of new drugs and the development of anaesthetic techniques which provide rapid and predictable recovery, and possibly, early hospital discharge. Although the influence of specific anaestheric drugs on both early and late recovery times has been evaluated in a number of studies, the cost-benefit of many techniques has not been clearly established. ${ }^{6,12,13}$ In the current investigation, shorter times to awakening and recovery of psychomotor function were observed with alfentanil/ $\mathrm{N}_{2} \mathrm{O}$ anaesthesia compared with inhalational anaesthesia and TIVA. Despite a higher incidence of nausea and vomiting in the alfen$\operatorname{tanil} / \mathrm{N}_{2} \mathrm{O}$ group, nursing requirements in the postanaesthesia care unit were not increased. Furthermore, clinically important differences in recovery variables, hospital discharge times, and the costs of recovery care were not observed beyond $30 \mathrm{~min}$ after emergence from anaesthesia. In view of lower costs associated with isoflurane $/ \mathrm{N}_{2} \mathrm{O}$ fentanyl anaesthesia, a possible pharmacoeconomic benefit may exist for this anaesthetic technique during brief ambulatory surgery procedures.

The recovery profile associated with isoflurane anaesthesia contrasts, to a certain extent, with observations from other studies, which report more rapid emergence following propofol anaesthesia. ${ }^{5}$ However, in such studies, patients typically receive a variable-rate infusion of propofol $\left(100-200 \mu \mathrm{g} \cdot \mathrm{kg}^{-1} \cdot \mathrm{min}^{-1}\right)$ in conjunction with $70 \% \mathrm{~N}_{2} \mathrm{O}$. In the current study, a fixedrate infusion of propofol $\left(140 \mu \mathrm{jg} \cdot \mathrm{kg}^{-1} \cdot \mathrm{min}^{-1}\right)$ was administered without $\mathrm{N}_{2} \mathrm{O}$, while analgesia was supplemented by intermittent boluses of alfentanil throughout the procedure. It is conceivable that more rapid emergence would have been observed in the TIVA group, had the propofol infusion rate been decreased towards the end of surgery. However, the protocol did not permit progressive down-ward titration, due to the potential for awareness with recall when propofol is infused at rates below 120 $\mu \mathrm{g} \cdot \mathrm{kg}^{-1} \cdot \mathrm{min}^{-1}$ during total intravenous anaesthesia. ${ }^{14}$

Of many factors which may influence operating room efficiency, one important aspect to consider is the speed and predictability of emergence from general anaesthesia. In this regard, BAL anaesthesia using alfentanil/ $\mathrm{N}_{2} \mathrm{O}$ provided remarkably short awakening times $(2.2 \pm 1.5 \mathrm{~min})$, with a high degree of pre- dictability (as reflected by a small standard deviation). These findings are relevant, as delays in the operating room can be very expensive, when considering that "OR time" may cost anywhere between $\$ 5-15$ per minute (based on both labour and overhead costs). Cumulative costs of OR delays may be realized either through the direct additional costs of overtime salaries of operating room personnel, or indirect costs resulting from case cancellation. These factors would suggest that somewhat higher drug costs of certain anaesthetic regimens may be amply justified if they enhance the speed of early recovery. However, these arguments must be interpreted with caution, because many $O R$ costs are relatively fixed.

Interestingly, an assumption that postoperative nausea and vomiting may increase hospital discharge time does not appear to be well supported. The current study demonstrates that the higher incidence of postoperative nausea and vomiting observed with BAL anaesthesia, prolonged neither PACU nor hospital lengths of stay. Similar findings have been reported by others. ${ }^{15,16}$ In one of these studies, Dexter and Tinker analyzed strategies to decrease post-anaesthesia care unit costs, and found that the primary factor influencing costs of PACU care is the distribution of admissions. ${ }^{16}$ Furthermore, these authors suggest that if nausea and vomiting could have been eliminated in each patient who suffered this complication, without causing sedation, that the total time of discharge for all patients would have been decreased by less than $4.8 \%$. Their data further led to the suggestion that anaesthetists have relatively little control over PACU economics via the choice of anaesthetic drugs.

Despite short-lived differences in several variables of early recovery, post-operatively the mean nursing workload, and PACU and DCU lengths of stay were similar in all three groups. Of equal relevance, hospital discharge times were also similar. While it may be more important in pharmacoeconomic evaluations to compare recovery criteria rather than actual discharge times, patients in all three groups were considered street-fit approximately $30 \mathrm{~min}$ earlier than their actual discharge times, according to their PADS scores. The reason for not having discharged patients more quickly, was an institutional policy in existence at the time of the study, requiring that patients remain for at least one half hour in the Day Care Unit following their arrival from PACU. Indeed, a shift towards timing the discharge of ambulatory surgery patients based on specific recovery criteria rather than an arbitrary time, has become common practice in many institutions across North America. Potential cost-savings may be considerable, but can only be realized if a 
decrease in total workload allows a given number of patients to be managed by fewer nurses within a given cost centre.

\section{Limitations of Current Investigation}

Several aspects of the study design merit special comment. First, different opioids were administered, in different relative doses, amongst the three groups. While a single dose of fentanyl was given to patients in the inhalational group, small boluses of alfentanil were given throughout surgery to patients who received balanced anaesthesia and TIVA. In the first group, fentanyl was chosen as the "standard" opioid analgesic, while in the latter two groups, alfentanil was selected due to the rapid recovery from its effects when administered as a single $i v$ bolus. ${ }^{17}$ Accordingly, no attempt was made to ensure equivalence of opioid effect between groups. Instead, emphasis was based upon a comparison of contemporary techniques of general anaesthesia, with regard to overall cost-effectiveness. Through careful standardization of both the study population and the surgical procedure, many potentially confounding variables were eliminated, and provide additional validity to the data.

Another limitation of this study relates to the lack of specific analytical tools relevant to the conduct of pharmacoeconomic evaluations in anaesthesia. While the general aim of pharmacoeconomics is to analyze the costs of drug therapy to health care systems and society, $i e$. to identify the total cost of treatment and not simply the cheapest drug or combination of drugs, ${ }^{18}$ one problem in anaesthesia lies in accurate quantification of the total costs of "treatment." The challenge lies partially in the fact that the conduct of anaesthesia is not a therapeutic modality per se. Consequently, while many side effects of anaesthesia may have important pharmacoeconomic consequences, some may not be strictly attributable to the anaesthetic itself. For example, postoperative nausea and vomiting are important untoward effects which have measurable indirect costs. However, the contributory influence of post-operative analgesic medications and the surgical procedure may be equally important, while simultaneously obscuring anaesthesiarelated effects. Thus, application of traditional pharmacoeconomic tools, such as cost-benefit analysis and cost-utility analysis, may not be as readily applicable in anaesthesia as they are in other areas of medicine. Future. studies should be directed to the development of pharmacoeconomic models relevant to our specialty.

\section{Conclusions}

For arthroscopic knee surgery, INH anaesthesia with isoflurane/fentanyl $/ \mathrm{N}_{2} \mathrm{O}$ is associated with similar hospital discharge times, and comparable levels of patient satisfaction as either BAL or TIVA. Alfentanil/ $\mathrm{N}_{2} \mathrm{O}$ anaesthesia results in the most rapid time to awakening, but a higher incidence of post-operative nausea and vomiting. Overall, isoflurane/fentanyl $/ \mathrm{N}_{2} \mathrm{O}$ anaesthesia had the lowest direct costs, and similar indirect costs. Accordingly, there appears to be a potential pharmacoeconomic benefit associated with the use of a "standard" isoflurane/fentanyl $/ \mathrm{N}_{2} \mathrm{O}$ anaesthetic for brief outpatient surgery. Potential cost-benefits associated with the new inhalational anaesthetics desflurane and sevoflurane, remain to be established.

\section{Acknowledgement}

We are grateful for the willing participation of the many patients who made this study possible. We also thank the nurses of PACU and DCU for their cooperation.

\section{References}

1 Hudson RJ, Friesen RM. Health care "reform" and the costs of anaesthesia (Editorial). Can J Anaesth 1993; 40: 1120-5.

2 Hawkes C, Miller D, Martineau R, Hull K, Hopkins $H$, Tiernay $M$. Evaluation of cost minimization strategies of anaesthetic drugs in a tertiary care hospital. Can J Anaesth 1994; 41: 894-901.

3 Johnstone RE, Jozefczyk KG. Costs of anesthetic drugs: experiences with a cost education trial. Anesth Analg 1994; 78: 766-71.

4 Orkin FK. Moving toward value-based anesthesia care. J Clin Anesth 1993; 5: 91-8.

5 Sung $Y-F$, Reiss $N$, Tillette $T$. The differential cost of anesthesia and recovery with propofolnitrous oxide anesthesia versus thiopental sodium-isoflurane-nitrous oxide anesthesia. J Clin Anesth 1991; 3: 391-4.

6 Todd MM, Warner DS, Sokoll MD, et al. A prospective, comparative trial of three anesthetics for elective supratentorial craniotomy. Propofol/fentanyl, isoflurane/nitrous oxide, and fentanyl/nitrous oxide. Anesthesiology 1993; 78: 1005-20.

7 Aldrete JA, Kroulik D. A postanaesthetic recovery score. Anesth Analg 1970; 49: 924-33.

8 Chung $F$, Ong D, Seyone C, Mati N, Powell P, Chan V. A new postanesthetic discharge scoring system for ambulatory surgery. Anesth Analg 1991; 72: S42.

9 Chernik $D A$, Gillings $D$, Laine $H$, et al. Validity and reliability of the observer's assessment of alertness/sedation scale: study with intravenous midazolam. J Clin Psychopharmacol 1990; 10: 244-51.

10 Newman $M G$, Trieger N, Miller JC. Measuring recovery from anesthesia - a simple test. Anesth Analg 1969; 48: $136-40$.

11 Wetchler $B V$. Economic impact of anesthesia decision making: they pay the money, we make the choice. J Clin Anesth 1992; 4: 20S-4. 
12 Cade L, Morley PT, Ross AW. Is propofol cost-effective for day-surgery patients? Anaesth Intensive Care 1991; 19: 201-4.

13 Miller DR. Anaesthesia drug costs and utilization - time for a critical re-appraisal (Editorial). Can J Anaesth 1996; 43: 4-8.

14 Miller DR, Blew PG, Martineau RJ, Hull KA. Midazolam and awareness with recall during total intravenous anaesthesia. Can J Anaesth 1996; 43: 946-53.

15 Dexter F, Tinker JH. Analysis of strategies to decrease postanesthesia care unit costs. Anesthesiology 1995; 82: 94-101.

16 Davis PJ, McGowan FX Jr, Landsman I, Maloney $K$, Hoffmann P. Effect of antiemetic therapy on recovery and hospital discharge time. Anesthesiology 1995; 83: 956-60.

17 Shafer SL, Varvel JR. Pharmacokinetics, pharmacodynamics, and rational opioid selection. Anesthesiology 1991; 74: 53-63.

18 Bevan DR. Anaesthesia pharmacoeconomics (Editorial). Can J Anaesth 1993; 40: 693-5. 